\title{
Mechanochemical Synthesis and Characterization of II-VI Nanocrystals: Challenge for Cytotoxicity Issues
}

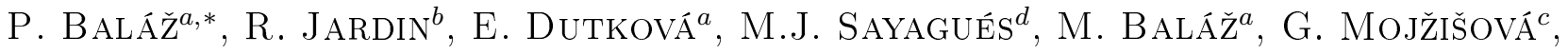 \\ J. MOJŽIS $\check{S}^{c}$, E. TURIANICOVÁ ${ }^{a}$ AND M. FABIÁN ${ }^{a}$ \\ ${ }^{a}$ Institute of Geotechnics, Slovak Academy of Sciences, Watsonova 45, 04353 Košice, Slovakia \\ ${ }^{b}$ Bruker AXS GmbH, Karlsruhe, Germany \\ ${ }^{c}$ P.J. Šafárik University, Faculty of Medicine, Košice, Slovakia \\ ${ }^{d}$ Institute of Materials Science of Seville, Sevilla, Spain
}

(Received September 22, 2011; in final form February 15, 2012)

\begin{abstract}
CdSe@ZnS nanocrystals have been prepared by a two-step solid state mechanochemical synthesis. CdSe prepared from elements in the first step is mixed with $\mathrm{ZnS}$ synthesized from zinc acetate and sodium sulfide in the second step. The crystallite size of the new type CdSe@ZnS nanocrystals determined by X-ray diffraction Rietveld refined method was $35 \mathrm{~nm}$ and $10 \mathrm{~nm}$ for CdSe and $\mathrm{ZnS}$, respectively. Energy dispersive/transmission electron microscopy/energy dispersive spectroscopy methods show good crystallinity of the nanoparticles and scanning electron microscopy elemental mapping illustrate consistent distribution of Cd, Se, Zn and S elements in the bulk of samples. UV-VIS spectra show an onset at $320 \mathrm{~nm}$ with calculated bandgap $3.85 \mathrm{eV}$. This absorption arises from the vibration modes of $\mathrm{Zn}-\mathrm{S}$ bonds. The nanocrystals show the blue shift from the bandgap of bulk $\mathrm{ZnS}$ $(3.66 \mathrm{eV})$. The synthesized CdSe@ZnS nanocrystals have been tested for dissolution, cytotoxicity and L-cysteine conjugation. The dissolution of $\mathrm{Cd}$ was less than $0.05 \mu \mathrm{g} \mathrm{mL} \mathrm{m}^{-1}$ (in comparison with $0.8 \mu \mathrm{g} \mathrm{mL} \mathrm{mL}^{-1}$ which was evidenced for CdSe alone). The very low cytotoxic activity for selected cancer cell lines has been evidenced. CdSe@ZnS nanocrystals coated with L-cysteine are water-soluble and have a great potential in biomedical engineering as fluorescent labels.
\end{abstract}

PACS: 81.05.Dz, 81.07.Bc, 81.20.Ka, 81.20.Wk

\section{Introduction}

Semiconductor nanocrystals appear to be interesting objects for studying basically novel properties of matter, generally described as "size quantization effects". In principle, the electronic and optical properties of semiconductor nanocrystals are tunable by varying their shape and size [1]. In recent years research into properties of semiconductor nanocrystals moved from basic research to applications in material and life sciences [2]. CdSe-core quantum dots represent a new nanomaterial which thanks to its optical properties has been shown to be a useful alternative to fluorescent dyes [3-5].

In previous works on cadmium-chalcogenide nanocrystals, a high-temperature organometallic procedure with the solvent tri- $n$-octylphosphine oxide in an inert atmosphere was used [6]. Cadmium organics have been later substituted by use of greener $\mathrm{Cd}$ sources such as cadmium acetate, carbonate, or oxide [7]. However, this

\footnotetext{
* corresponding author; e-mail: balaz@saske.sk
}

"green" synthetic strategy did not lead to the elimination of Cd-toxicity [8], which is the main issue with semiconductor nanocrystals as fluorescent labels. This toxicity correlates with surface oxidation, decrease of size of nanocrystals and disruption of crystal lattice. The choice of $\mathrm{ZnS}$ as a shell for the capping of CdSe cores is guided by the need for a semiconductor with a wider bandgap than the core [9]. The addition of $\mathrm{ZnS}$ surface coating results in the increase of the quantum yield and stability of nanocrystals, the decrease of the surface oxidation and resulting cytotoxicity [4]. ZnS shell passivates the CdSe core surface, protects it from oxidation, prevents the leakage of the cadmium and selen into surrounding solution and also improves the optical properties [10]. Moreover, surface sulfur atoms of $\mathrm{ZnS}$ can be made water-soluble via surface modification by using biomacromolecules [11, 12].

However, only the high-temperature solvent/ligand mixtures have been applied in the synthesis of CdSe@ZnS nanocrystals till now $[9,10]$. Therefore, a search for the new synthetic methods is a reasonable direction. Here the mechanochemical way seemed to be an appropriate choice. 


\section{Experimental}

\subsection{Materials}

Cadmium (99.5\% Aldrich, Germany), selenium (99.5\% Aldrich, Germany), zinc acetate $\left(\mathrm{CH}_{3} \mathrm{COO}\right)_{2} \mathrm{Zn} \cdot 2 \mathrm{H}_{2} \mathrm{O}$ and sodium sulphide $\mathrm{Na}_{2} \mathrm{~S} \cdot 9 \mathrm{H}_{2} \mathrm{O}$ (ITES, Slovakia) were supplied as reaction precursors. L-cysteine (Aldrich, Japan) was used as capping agent.

The mechanochemical synthesis of the nanoparticles was performed in a Pulverisette 6 planetary mill (Fritsch, Germany). The following milling conditions were used - loading of the mill: 50 balls of $10 \mathrm{~mm}$ diameter; ball charge in the mill: $360 \mathrm{~g}$; material of milling chamber and balls: tungsten carbide; rotation speed of the planet carrier: 500 rpm; using an argon atmosphere as a protective medium in the mill; milling time $120 \mathrm{~min}$ and $20 \mathrm{~min}$ for CdSe (milling I) and CdSe@ZnS (milling II), respectively. In milling I the stoichiometric mixture of $\mathrm{Cd}$ and Se were milled in order to prepare $6 \mathrm{~g}$ of CdSe product. In milling II the stoichiometric mixtures of zinc acetate $\left(\mathrm{CH}_{3} \mathrm{COO}\right)_{2} \mathrm{Zn} \cdot 2 \mathrm{H}_{2} \mathrm{O}$ and sodium sulphide $\mathrm{Na}_{2} \mathrm{~S} \cdot 9 \mathrm{H}_{2} \mathrm{O}$ were added into the mill and further milled to prepare $12 \mathrm{~g}$ of CdSe@ZnS. The flowchart of the synthesis process and the further processing is given in Fig. 1.

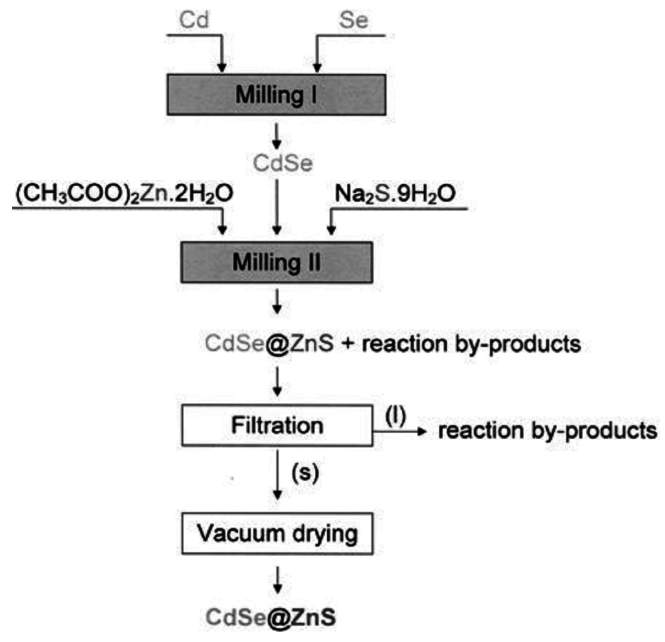

Fig. 1. Preparation of CdSe@ZnS nanocrystals through mechanochemical synthesis.

CdSe@ZnS nanocrystals have been synthesized in the mill according to the following equations (1), (2):

$$
\begin{aligned}
& \mathrm{Cd}+\mathrm{Se} \rightarrow \mathrm{CdSe}, \\
& \mathrm{CdSe}+\left(\mathrm{CH}_{3} \mathrm{COO}\right)_{2} \mathrm{Zn} \cdot 2 \mathrm{H}_{2} \mathrm{O}+\mathrm{Na}_{2} \mathrm{~S} \cdot 9 \mathrm{H}_{2} \mathrm{O} \\
& \quad \rightarrow \mathrm{CdSe} @ \mathrm{ZnS}+2 \mathrm{CH}_{3} \mathrm{COONa}+11 \mathrm{H}_{2} \mathrm{O} .
\end{aligned}
$$

In separate experiments CdSe@ZnS nanocrystals have been capped with L-cysteine using co-milling of CdSe@ZnS with $0.1243 \mathrm{~g} \mathrm{~mL}^{-1}$ L-cysteine for $30 \mathrm{~min}$ at rotation of the planet carrier $500 \mathrm{~min}^{-1}$. After co-milling the sample was washed out several times with distilled water.

\subsection{Characterization methods}

X-ray diffraction (XRD) measurements to perform the phase identification and the crystallite size determination were made with a D8 ADVANCE diffractometer (Bruker, Germany) in theta-theta configuration in the Bragg-Brentano geometry. The LynxEye TM fast linear detector was used. The sample was prepared in silicon low background sample holder and measured from 15 to $120^{\circ}$. The step size was $0.04^{\circ}$ and the counting time was set to $2 \mathrm{~s}$ per step. A phase identification was performed using the DiffracPlus EVA software combined with the PDF4 + database. The crystallite size determination was performed using the DiffracPlus TOPAS software (Bruker).

Optical studies were carried out using UV-VIS spectrophotometer HELIOS GAMMA (Thermo, Great Britain) in the range $200-700 \mathrm{~nm}$ in quartz cell by dispersing the synthesized nanoparticles in absolute ethanol by ultrasonification.

For infrared spectroscopy study the IR spectrophotometer AVATAR FTIR 330 (Thermo-Nicolet, USA) was used in the frequency range $4000-400 \mathrm{~cm}^{-1}$ using $\mathrm{KBr}$ pellet method.

Compositional analysis at microstructural level was carried out using a scanning electron microscopy (SEM) and energy dispersive X-ray (EDX) techniques. A field emission gun (FEG) scanning electron microscope (Hitachi S-4800) equipped with Bruker Quantax microanalysis based on energy-dispersed spectrometry was used.

\subsection{Dissolution tests}

The dissolution tests were conducted in a $500 \mathrm{~mL}$ glass reactor under the following conditions: sample (CdSe or CdSe@ZnS nanocrystals) $0.5 \mathrm{~g}$, volume of physiological solution $(0.9 \% \mathrm{NaCl}) 400 \mathrm{~mL}$, temperature $310 \mathrm{~K}$. Aliquots $(5 \mathrm{~mL})$ of the solution were withdrawn at appropriate time intervals for determination of dissolved cadmium by atomic absorption spectroscopy method.

\subsubsection{Tumor cell lines}

\subsection{Antineoplastic activity}

MCF-7 (human breast adenocarcinoma, estrogen receptor-positive) and A-549 (human lung adenocarcinoma) cell lines were kindly provided by Dr. M. Hajdúch (Olomouc, Czech Republic). The cells were routinely maintained in Dulbecco's modified Eagle's medium with Glutamax-I supplemented with $10 \%$ fetal calf serum, penicillin $\left(100 \mu \mathrm{g} \mathrm{mL}{ }^{-1}\right)$ and streptomycin $\left(100 \mu \mathrm{g} \mathrm{mL}^{-1}\right)$ (all from Invitrogen, USA), in humidified air with $5 \% \mathrm{CO}_{2}$ at $37^{\circ} \mathrm{C}$. Before each cytotoxicity assay, cell viability was determined by trypan blue exclusion method and found greater than $95 \%$.

\subsubsection{Cytotoxicity assay}

The cytotoxic effects of compounds were determined colourimetrically with the 3-(4,5-dimethyltiazol-2-yl)2,5-diphenyltetrazolium bromide (MTT) (Sigma, Germany) end-point method. Briefly, $3 \times 10^{3}$ cells were 
plated per well in 96-well polystyrene microplates (Sarstedt, Germany) in the culture medium containing tested nanocrystals at final concentrations of $5.95 \% \mathrm{Cd}$ (for CdSe) and $5.65 \% \mathrm{Cd}+7.45 \% \mathrm{Zn}$ (for CdSe@ZnS). After $72 \mathrm{~h}$ of incubation, $10 \mu \mathrm{L}$ of MTT $\left(5 \mathrm{mg} \mathrm{mL}{ }^{-1}\right)$ were added in each well. After additional $4 \mathrm{~h}$, during which insoluble formazan was produced, $100 \mu \mathrm{L}$ of $10 \%$ sodium dodecylsulphate were added in each well and another $12 \mathrm{~h}$ were allowed for the dissolution of formazan. Absorbance was measured at $540 \mathrm{~nm}$ using the automated MRX microplate reader (Dynatech Laboratories, UK). The blank-corrected absorbance of the control wells was taken as $100 \%$ and the results were expressed as a percentage of the control. All experiments were performed in triplicate.

\section{Results and discussion}

Figure 2 shows the X-ray diffraction patterns of products of mechanochemical synthesis. Within $120 \mathrm{~min}$ of milling I $\{111\},\{220\},\{311\},\{400\},\{331\}$ and $\{422\}$ lattice planes of CdSe can be assigned to the observed diffraction peaks. However, in case of CdSe@ZnS nanocrystals, it is difficult to discriminate zinc blende structure. In case of longer milling, a shift from wurtzite

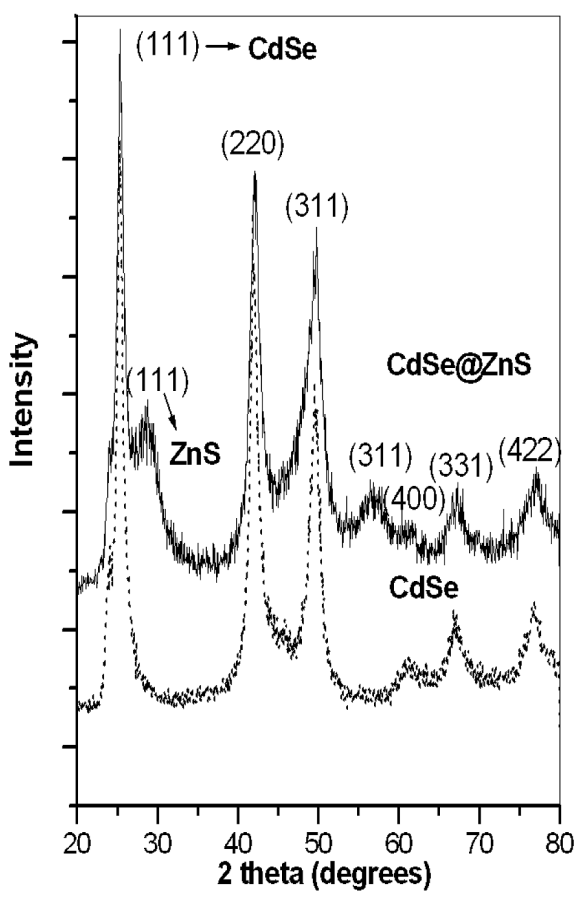

Fig. 2. XRD patterns of CdSe and CdSe@ZnS nanocrystals.

phase to zinc blende structure has been documented in literature [12]. Milling II aimed at $\mathrm{ZnS}$ synthesis has shown the presence of $\{111\}$ and $\{311\}$ lattice planes as the first and the third dominant peaks of a hexagonal $\mathrm{ZnS}$ phase [14]. However, the second dominant peak with $\{220\}$ is masked due to a large broadening of the reflection $\{311\}$ lattice plane of CdSe. Generally, amorphization effects are bigger in the case of $\mathrm{ZnS}$; this is in perfect agreement with the calculated crystallite size of both components. Indeed, refined calculated values from XRD data are about $35 \mathrm{~nm}$ and $10 \mathrm{~nm}$ for CdSe and $\mathrm{ZnS}$ nanocrystals, respectively.

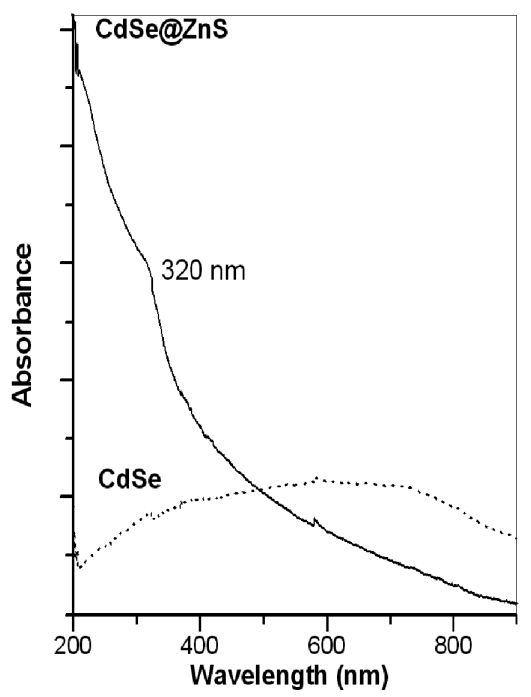

Fig. 3. UV-VIS spectra of CdSe and CdSe@ZnS nanocrystals.

UV-VIS spectra of the mechanochemically synthesized nanocrystals of CdSe and CdSe@ZnS are given in Fig. 3. The plot for CdSe shows no absorption edge due to any blue shift of the indirect bandgap energy of $1.74 \mathrm{eV}$. It appeared that the mechanochemically synthesized CdSe nanoparticles did not behave as quantum dots. In the case of CdSe capped with $\mathrm{ZnS}$ there is only an onset at $320 \mathrm{~nm}$ with the calculated bandgap $3.85 \mathrm{eV}$. This absorption probably arises from the vibration modes of $\mathrm{Zn}-\mathrm{S}$ on the surface of CdSe. It shows size-dependent effect of quantum confinement and assigns the blue shift from the direct bandgap energy $3.66 \mathrm{eV}$ of bulk $\mathrm{ZnS}$. It is in a good accordance with the XRD analysis where smaller crystallite size of $\mathrm{ZnS}$ particles $(10 \mathrm{~nm})$ and larger crystallite size of CdSe particles ( $35 \mathrm{~nm}$ ) have been determined.

The SEM analysis together with the elemental mapping is given in Fig. 4. Figure 4a shows a SEM micrograph (taken with secondary electrons) of an area of the CdSe@ZnS sample where there can be seen that the powder sample is formed by quite agglomerated small particles. Chemical analysis performed by EDX confirmed the chemical distribution of all components in the sample. The corresponding EDX spectrum is presented in Fig. $4 \mathrm{~b}$, where the present elements in nanocrystals can be appreciated. To analyse the chemical distribution in this region an element mapping analysis was performed using the $K$ edges for $\mathrm{Zn}$ and $\mathrm{S}$ (green and red) and $L$ edges for $\mathrm{Cd}$ and Se (light and dark blue) elements and the obtained results are presented in Fig. $4 \mathrm{c}-\mathrm{f}$. The two 
ZnS and CdSe phases appear homogeneously distributed in the nanocomposite material. The $\mathrm{Zn}$ and $\mathrm{S}$ signals are higher than $\mathrm{Cd}$ and $\mathrm{S}$ signals in concordance with the sample composition. The compositional mapping (addi- tion of the four elemental signals) is presented in Fig. $4 \mathrm{~g}$. A small region richer in CdSe can be observed an the bottom of the figure (blue colour).
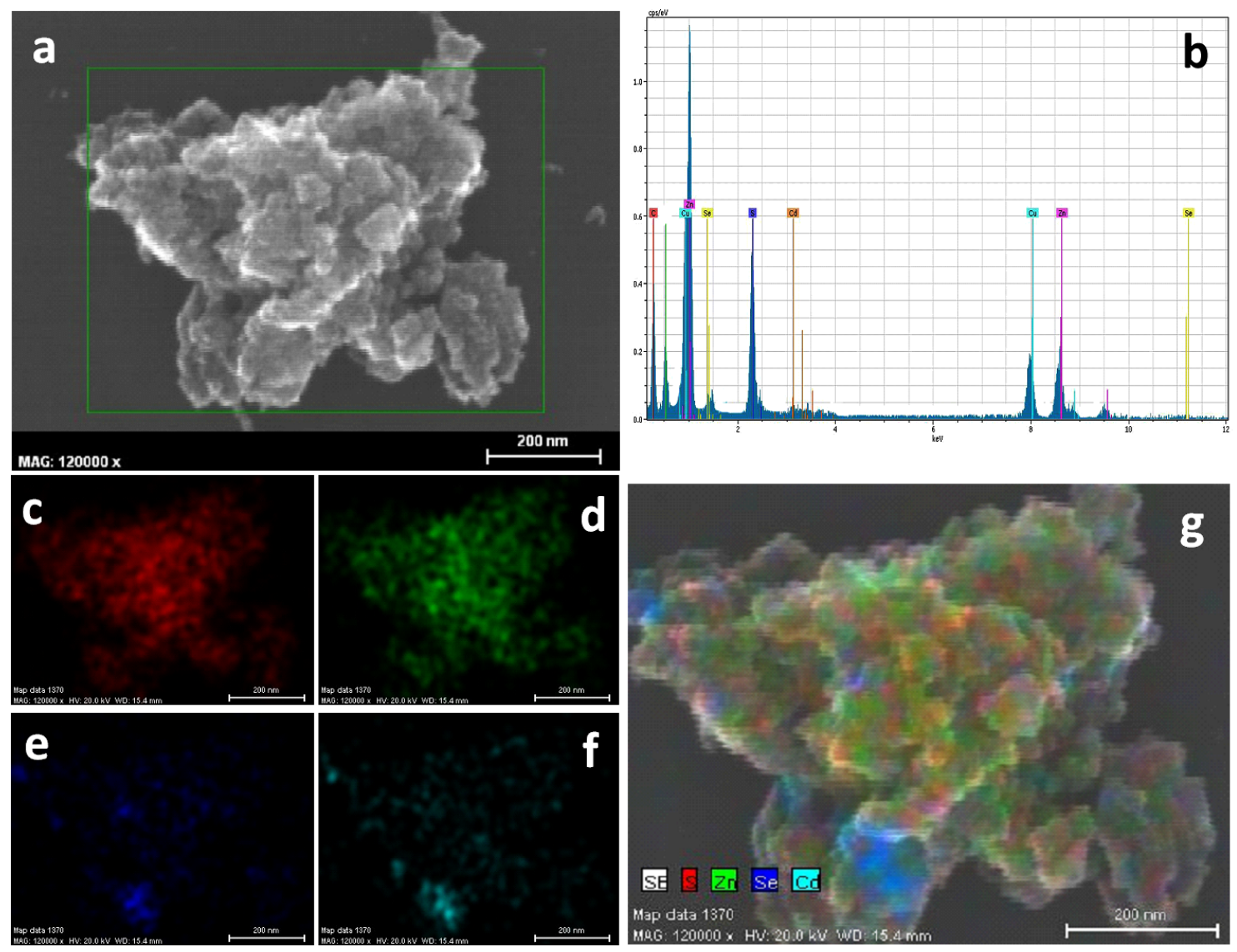

Fig. 4. SEM (a), EDX (b) and FEG (c-g) of CdSe@ZnS nanocrystals.

The infrared spectra of pure L-cysteine, CdSe@ZnS co-milled with L-cysteine and pure L-cystine are given in Fig. 5.

In the spectrum of pure L-cysteine (Fig. 5a), the peak around $2550 \mathrm{~cm}^{-1}$, which corresponds to the stretching vibration of the $-\mathrm{SH}$ group is present [15]. The peak at $1380 \mathrm{~cm}^{-1}$ corresponds to the symmetric stretching vibration of $-\mathrm{COO}^{-}$group and the peak at $1580 \mathrm{~cm}^{-1}$ corresponds to the asymmetric bending vibration of the $-\mathrm{NH}_{3}^{+}$group [15].

In the spectrum of pure L-cystine (Fig. 5c), the broad strong peak at $3024 \mathrm{~cm}^{-1}$ corresponds to the stretching vibration of $-\mathrm{NH}_{3}^{+}$group [16]. The two peaks mentioned above, when talking about the spectrum of L-cysteine at 1380 and $1580 \mathrm{~cm}^{-1}$ are also present in this spectrum at similar wave number.

Firstly we compared the spectrum of CdSe@ZnS co-milled with L-cysteine (Fig. 5b) to the spectrum of pure L-cysteine. We found out that some peaks are missing and some new are present. The most significant change is the disappearance of the peak corresponding to the $-\mathrm{SH}$ group vibration.

When we compared the obtained spectrum of CdSe@ZnS co-milled with L-cysteine with the spectrum of pure L-cystine, we found out that they are the same. The presence of the two peaks in the region around 1380 and $1580 \mathrm{~cm}^{-1}$ also in this spectrum confirms that these groups are free [15].

We conclude that L-cystine is formed from L-cysteine during the milling process. The mechanical transformation of L-cysteine to L-cystine occurs according to the oxidation process [17], which takes place because of the presence of air and water during milling. Recently, we have taken a closer look at the mechanical transformations of L-cysteine alone. The results show that water plays the key role in the mechanochemical transformation of L-cysteine. In the presence of water, L-cystine is formed by oxidation, but when dry L-cysteine powder in 


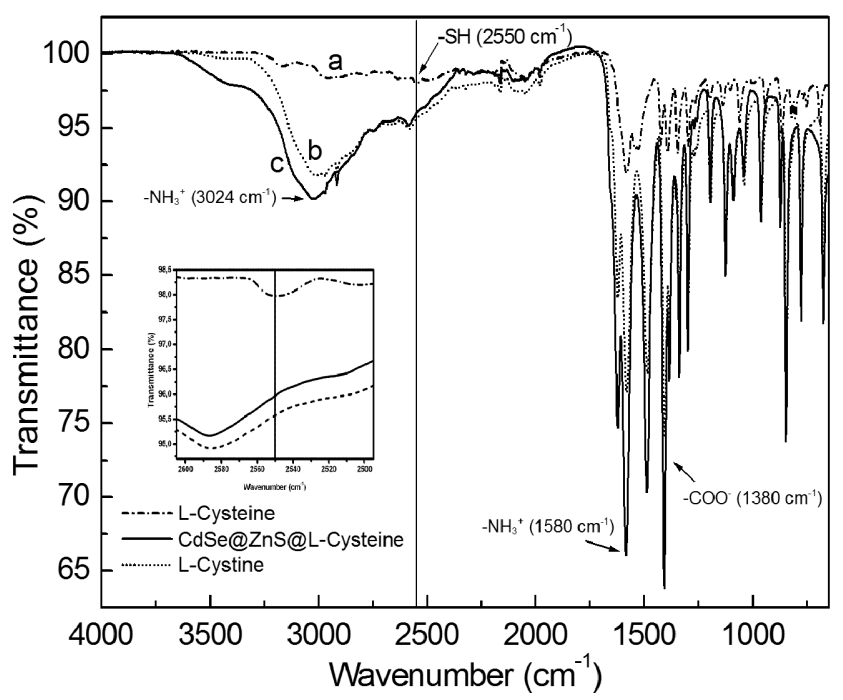

Fig. 5. The IR spectra of pure L-cysteine (a), CdSe@ZnS nanocrystals co-milled with L-cysteine (b) and pure L-cystine (c).

solid state is treated at the same conditions, it remains unchanged.

We also conclude that L-cystine is bound to the CdSe@ZnS nanoparticles. The question concerning the exact type of bonds remains unanswered, however our recent experiments have shown that L-cystine is bound to the $\mathrm{ZnS}$ part. On the other hand, there are no changes visible in the infrared spectra, when we compare the spectrum of pure L-cystine (Fig. 5c) and the spectrum of CdSe@ZnS co-milled with L-cysteine (Fig. 5b). When there would be some covalent bond present, some change should occur in the spectrum of CdSe@ZnS sample co-milled with L-cysteine. We assume that there is some chemical bond present that does not affect the infrared spectra of the sample.

The dissolution activity of CdSe and CdSe@ZnS as a possible source of soluble cadmium ions is illustrated by Table. The average concentration of $\mathrm{Cd}=0.8 \mu \mathrm{g} \mathrm{mL}^{-1}$ for CdSe nanocrystals was attained after $30 \mathrm{~min}$ of dissolution in a physiological medium $(0.9 \% \mathrm{NaCl})$ at human body temperature $(310 \mathrm{~K})$. However, in case of the CdSe@ZnS nanocrystals, this value was lower than $0.05 \mu \mathrm{g} \mathrm{mL} L^{-1}$. Clearly, cadmium leakage from CdSe@ZnS was depressed more than 16 times in comparison with the non-capped CdSe.

The cytotoxicity tests performed by standard method [18] for two selected cancer cell lines are illustrated in Fig. 6. Two dilutions of CdSe@ZnS nanoparticles resulting in different $\mathrm{Cd}$ and $\mathrm{Zn}$ concentrations have been applied. The viability of the cells is practically not influenced by the presence of CdSe@ZnS. In accordance with data in Table, where cadmium dissolution from CdSe@ZnS sample is practically depressed, we may conclude that the CdSe@ZnS nanocrystals are not cytotoxic for the cancer cell lines under study. The presence of $\mathrm{ZnS}$
TABLE

Concentration of cadmium in liquid phase after dissolution of CdSe and CdSe@ZnS nanocrystals.

\begin{tabular}{c|c|c}
\hline \hline $\begin{array}{c}\text { Dissolution time } \\
{[\mathrm{min}]}\end{array}$ & \multicolumn{2}{|c}{$\begin{array}{c}\text { Concentration of cadmium } \\
{\left[\mu \mathrm{gL}^{-1}\right]}\end{array}$} \\
\cline { 2 - 3 } & CdSe & CdSe@ZnS \\
\hline 1 & 1.1 & $<0.05^{*}$ \\
3 & 0.8 & $<0.05^{*}$ \\
5 & 0.8 & $<0.05^{*}$ \\
10 & 0.6 & $<0.05^{*}$ \\
20 & 0.8 & $<0.05^{*}$ \\
30 & 0.7 & $<0.05^{*}$ \\
\hline
\end{tabular}

* detection limit for Cd determination by atomic absorption method

in CdSe@ZnS species is probably the main reason why the release of toxic cadmium is practically eliminated. The mechanism has to be elucidated.

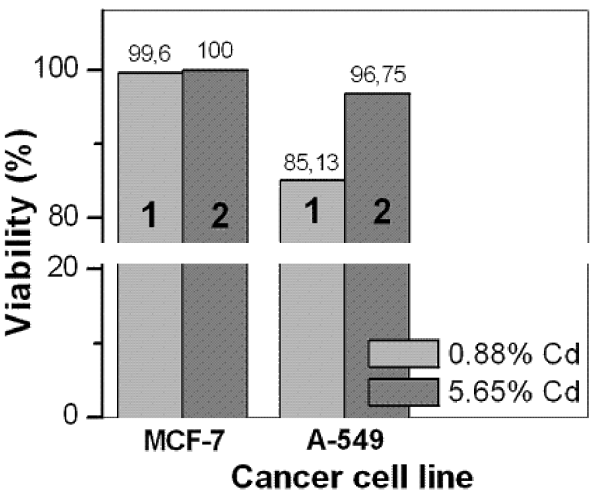

Fig. 6. Viability of two cancer cell lines (MCF-7 $=$ human breast adenocarcinoma, estrogen receptor-positive; A-549 = human lung carcinoma) in the presence of CdSe@ZnS nanocrystals $(1=0.88 \%$ Cd, $2=5.65 \%$ Cd $)$.

\section{Conclusions}

In summary, we have reported the solid state mechanochemical synthesis of CdSe@ZnS nanocrystals with crystallite size 35 and $10 \mathrm{~nm}$ for CdSe and $\mathrm{ZnS}$, respectively. Consistent distribution of $\mathrm{Cd}, \mathrm{Se}, \mathrm{Zn}$, and $\mathrm{S}$ elements in the bulk of nanocrystals was determined by elemental mapping. The new type of bulk nanocomposite show reduced dissolution of cadmium and practically no cytotoxicity for human cancer lines. Thus the obtained nanoparticles after modification can serve as an alternative to fluorescent dyes for use in biological imaging and/or for binding of drugs in theranostic studies.

\section{Acknowledgments}

The support through the Agency for Science and Development (project APVV-0189-10) and the Slovak Grant Agency (projects VEGA 2/0009/11 and VEGA $2 / 0139 / 10)$ is also gratefully acknowledged. 


\section{References}

[1] Semiconductor Nanocrystal Quantum Dots, Ed. A.L. Rogach, Springer, Wien 2008.

[2] W.J. Parak, D. Gerion, T. Pellegrino, D. Zanchet, Ch. Michael, S.C. Williams, R. Boudreau, M.A. Le Gros, C.A. Larabell, A.P. Alivisatos, Nanotechnology 14, R15 (2003).

[3] W.C. Chan, S. Nie, Science 281, 2016 (1998).

[4] A.M. Derfus, W.C.W. Chan, S.N. Bhatia, Nano Lett. 4, 11 (2004)

[5] W.H. Liu, H.S. Choi, J.P. Zimmer, E. Tanaka, J.V. Frangioni, M. Bawendi, J. Am. Chem. Soc. 129, 14530 (2007).

[6] J.E. Bowen-Katari, V.L. Colvin, A.P. Alivisatos, J. Phys. Chem. 98, 4109 (1994).

[7] Z.A. Peng, X. Peng, J. Am. Chem. Soc. 124, 3343 (2002).

[8] R. Hardman, Environ. Health Persp. 114, 165 (2006).

[9] M.A. Hines, P. Guyot-Sionnest, J. Phys. Chem. 100, 468 (1996).
[10] I.L. Medintz, H.T. Uyeda, E.R. Goldman, H. Mattoussi, Nat. Mater. 4, 435 (2005).

[11] H.Y. Xie, J.G. Liang, Y. Liu, Z.L. Zhang, D.W. Pang, Z.K. He, Z.X. Lu, W.H. Huang, J. Nanosci. Nanotechnol. 5, 880 (2005)

[12] H. Ehrlich, T. Scherba, M. Zhilenko, G. Lisichkin, Mater. Lett. 65, 107 (2011).

[13] G.L. Tan, J.H. Du, Q.J. Zhang, J. Alloy. Comp. 468, 421 (2009).

[14] E. Dutková, P. Baláž, P. Pourghahramani, S. Velumani, J.A. Ascencio, N.G. Kostova, J. Nanosci. Nanotechnol. 9, 6600 (2009).

[15] A. Chatterjee, A. Priryam, S.K. Das, A. Saha, J. Colloid Interf. Sci. 294, 334 (2006).

[16] P.K. Sapathy, G.C. Dash, P. Mohanty, Indian J. Chem. 47A, 1199 (2008).

[17] H. Bao, X. Cui, C.M. Li, J. Zang, Nanotechnology 18, 455701 (2007).

[18] T.J. Mosmann, J. Immunol. Meth. 65, 55 (1983). 